\title{
Tracheostomy Cannula Aspiration
}

\author{
Trakeostomi Kanülü Aspirasyonu
}
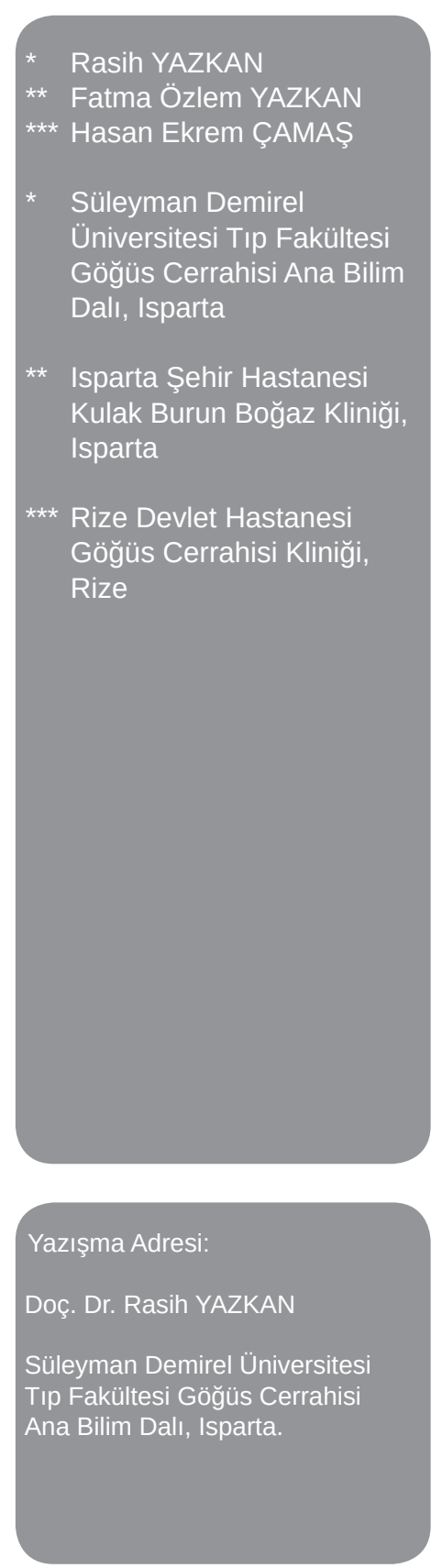

Anahtar Kelimeler : Kanül, aspirasyon, trakeostomi

Keywords: Cannula, aspiration, tracheostomy

Dear editor,

Foreign body aspiration is especially evident in developing countries, and often seen in babies and children. Foreign bodies usually identify in the right main bronchus system because it is larger than the left main bronchus system and more vertical towards the trachea. The nature of aspirated foreign bodies affects the clinical situation. The most frequently aspirated food, nuts, teeth, bones, and dental prostheses (1). Here we report a very rare case report, and we aimed to present brief information about foreign body aspirations In our case a 59 years old male tracheostomy patient aspirated his silver cannula in his left main bronchus following a forceful cough. Rigid bronchoscopy was performed to remove the cannula, which had granulation tissue and fibrinous deposit inside (Figure 1). We removed the cannula with strong pens.

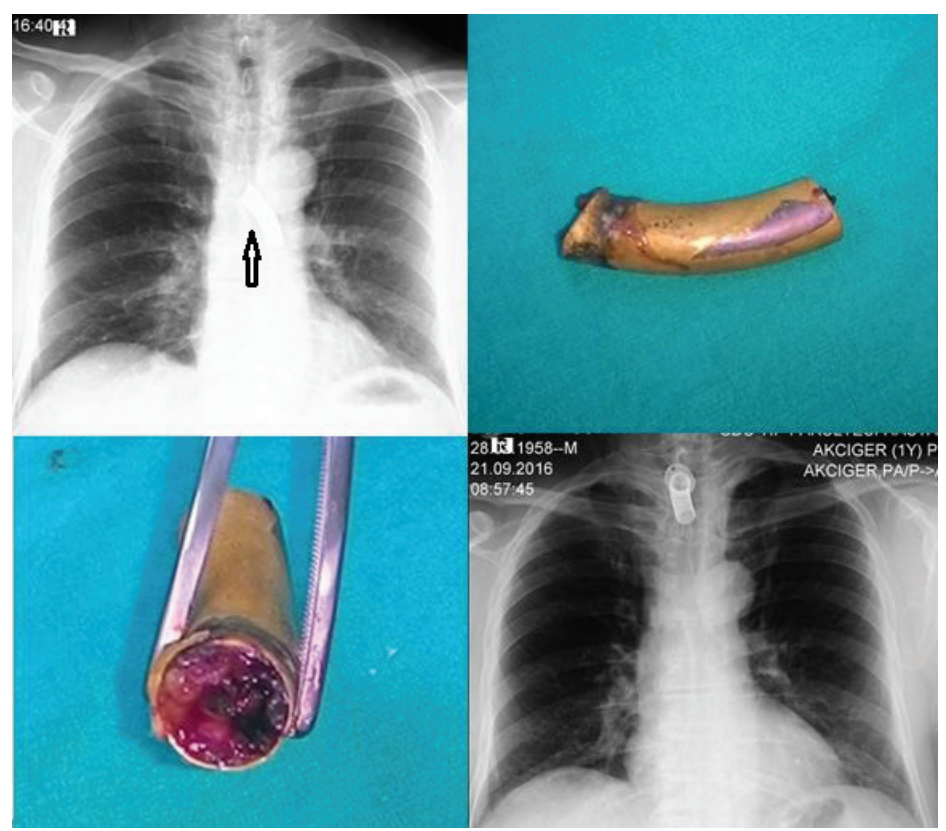

Figure 1: Aspirated cannula is showing with black arrow in chest x-ray, showing cannula after remowed, and chest x-ray after remowed. 
History is very important for diagnosis of foreign body aspiration. Cough is the most common symptom. Initially irritative, dry and spasmodic, and loses its violence after it has settled to the bronchus. Radiological examination should be performed on all suspected cases. Foreign body seldom obstruct the proximal airways fully, causing life-threatening asphyxia. Delayed foreign body removal may result in persistent pneumonia, bronchiectasis lung abscess, and excessive granulation tissue formation, sometimes simulating lung cancer.

Rigid bronchoscopy under general anesthesia provides safe airway control, particularly in patients with large or impacted foreign body, with respiratory failure, or clinically unstable due to aspiration. Fiberoptic bronchoscopy is not an acceptable approach. Delayed diagnosis, choice of the wrong instrument, inexperience, and no communication between anesthetist and surgeon are among the reasons of the complications, morbidity and mortality. Aspirations of fluid-swellable organic materials such as chickpeas and beans, partial or total airway obstruction, and aspiration of battery containing corrosive substances are requiring emergency bronchoscopy.

In conclusion, foreign body aspirations is a life threating condition, early diagnosis and rapid interventions are life saving approaches.

\section{References}

1. D'Agostino FG, Monaco F, Mondello B, Familiari D, Barone M. Management of a case of unacknowledged foreign body in the upper airway. Asian Cardiovascular \& Thoracic Annals 0(0) 1-3. DOI: $10.1177 / 0218492318783293$ 